\title{
Immunoblotting para diagnóstico de toxocarosis humana en un área subtropical
}

\author{
MARÍA DE LOS A. LÓPEZ*, MARÍA VIVIANA BOJANICH**, \\ MARÍA EUGENIA ALONSO* y JOSÉ MARIO ALONSO*
}

\section{IMMUNOBLOTTING FOR THE DIAGNOSIS OF HUMAN TOXOCAROSIS IN A SUBTROPICAL AREA}

The diagnosis of toxocarosis is based upon the demonstration of antibodies by ELISA methods, although cross-reaction with other ascarids may occur in populations from tropical areas. For this reason, some authors proposed western blotting as a confirmatory test. The aim of this work was to develop an immunoblotting in simpler technical conditions and to compare results with the ELISA test. With this purpose sera from adults and children with sign and/or symptoms of toxocarosis and living in the metropolitan area of Resistencia city (Northeast of Argentina) were studied. ELISA test was performed and 120 positives and 60 negatives sera were selected and analyzed again by immunoblotting. Positive samples and controls showed a WB pattern with six bands of $67.6 \mathrm{kDa}, 55.6$ $k D a, 43.9 k D a, 32.4 k D a, 26.6 \mathrm{kDa}$ and $23.4 \mathrm{kDa}$, while negative controls from endemic and nonendemic areas of toxocarosis showed no bands. Out of the 180 samples studied, in 172 coincident results for both methods were obtained (95.6\%), 6 ELISA negative samples were positive for WB (3.3\%) and 2 ELISA positive samples resulted negative in the WB (1.1\%). The immunoblotting technique described in this work may constitute an adequate method for the diagnosis of toxocarosis in subtropical areas, particularly useful in cases with negative or low-titers ELISA test results and with signs or symptoms of the infection.

Key words: Toxocarosis, western blot, Toxocara canis, serodiagnosis, ELISA.

\section{INTRODUCCIÓN}

La toxocarosis es una saprozoonosis poco reconocida como un problema relevante de salud pública. Su agente etiológico es el nematode Toxocara canis, un ascárido cuyo huésped definitivo es el perro y que llega al hombre a través de la ingesta de huevos embrionados, generalmente a partir del medio ambiente contaminado, provocando diferentes síndromes clínicos ${ }^{1}$.

El diagnóstico de la infección humana resulta dificultoso porque la sintomatología es poco

\footnotetext{
* Área de Inmunología, Instituto de Medicina Regional, Universidad Nacional del Nordeste, Resistencia, Argentina. ** Área de Microbiología. Facultad de Ciencias Exactas y Naturales y Agrimensura, Universidad Nacional del Nordeste, Corrientes, Argentina.

Correspondencia a: Dra. María de los A. López, Instituto de Medicina Regional, Universidad Nac. del Nordeste Av. Las Heras 727, 3500 - Resistencia, Argentina.

Fax: 54-3722-422793 e-mail: jalonso@bib.unne.edu.ar
} 
específica, el parásito adulto no se encuentra en las heces ni tampoco sus huevos y el hallazgo de las larvas en los tejidos mediante biopsias de los granulomas es un hecho excepcional. Por ello, la demostración de los anticuerpos específicos es la herramienta más útil y confiable ${ }^{2}$. Para esto se utilizan como antígeno a los productos metabólicos de las larvas $\mathrm{L}_{2}$ de $T$. canis, llamados Antígenos de excreción/secreción (TES), siendo el enzimo-inmunoensayo la técnica que más corrientemente se emplea ${ }^{2,3}$.

Los principales constituyentes de TES se han identificado como mucinas, lectinas y proteínas ligadoras de fosfatidiletanolamina, y se las designan como TES-32, TES-55, TES-70, etc de acuerdo a su peso molecular ${ }^{4}$. Si bien en los últimos años se ha logrado clonar y expresar los genes que codifican a varios de estos productos, aún no se los aplica en los métodos diagnósticos 5 .

Es bien conocido que en las pruebas serológicas pueden ocurrir reacciones cruzadas con antígenos de otros ascáridos, frecuentemente prevalentes en las regiones tropicales y subtropicales. Ante la ausencia de un método diagnóstico directo de referencia o "gold Standard" para toxocarosis y en la búsqueda de una metodología de mayor especificidad que ofrezca seguridad en el diagnóstico, varios autores han informado sobre la aplicación del Western Blot ya que esta prueba muestra un patrón de bandas característico que permite diferenciar la infección producida por otros parásitos, y por ello se ha propuesto a este método como prueba confirmatoria ${ }^{6,7}$.

Se conoce por trabajos anteriores que la toxocarosis es una infección de alta prevalencia entre la población adulta e infantil de la región metropolitana de la ciudad de Resistencia ${ }^{8,9}$, área ubicada en el noreste de Argentina, con clima subtropical y en la que también otras parasitosis son muy frecuentes ${ }^{10}$. Por ello, resulta necesario contar con un método diagnóstico de confirmación que permita eliminar reacciones cruzadas en los casos de pacientes con signos clínicos compatibles con toxocariosis y serología poco definitoria. Con este propósito se decidió desarrollar un método de inmunoblotting con condiciones técnicas más sencillas a las habitualmente descriptas y comparar su desempeño con la reacción de enzimoinmunoensayo. Se presentan en este informe las condiciones técnicas aplicadas y el comportamiento encontrado de la prueba.

\section{MATERIAL Y MÉTODOS}

Sueros: Se trabajó con 180 muestras de suero de 70 adultos y 110 niños de recién nacidos a 16 años de edad, de ambos sexos, residentes permanentes en el área metropolitana de la ciudad de Resistencia y con signo-sintomatología básica compatible con toxocariaosis (IgE total aumentada y eosinofilia igual o mayor al 10\%). Los sueros ya habían sido estudiados con anterioridad mediante la prueba de ELISA para $T$. canis y se encontraban depositados en la seroteca de la Institución. Se seleccionaron 120 sueros ELISA positivos y 60 negativos, se los analizó nuevamente por el mismo método y por "Immunobloting" y se compararon los resultados.

Como controles negativos se emplearon 5 sueros humanos normales, procedentes de un área urbana donde la infección por T. canis es no endémica (Santiago de Compostela, España) y 5 sueros de adultos sanos de la ciudad de Resistencia con IgE y recuento de eosinófilos dentro de los valores normales. Como control positivo se empleó 2 sueros procedentes del Instituto Nacional de Microbiología y Enfermedades Infecciosas "Dr. Carlos G. Malbrán” de la ciudad de Buenos Aires.

Obtención de los Antígenos TES: fueron obtenidos según técnica descripta ${ }^{11}$, a partir de larvas $\mathrm{L}_{2}$ de $T$. canis, mantenidas viables en medio de cultivo de Dulbecco, modificación de Iscove, con el agregado de buffer Hepes y de penicilinaestreptomicina. Fueron incubadas a $37^{\circ} \mathrm{C}$ en atmósfera con $5 \%$ de $\mathrm{CO}_{2}$ ajustando el $\mathrm{pH}$ a $6,4-$ $6,5^{12}$. Semanalmente se colectó el medio de cultivo sobrenadante, formando un pool que se conservó a $-70^{\circ} \mathrm{C}$. Luego se concentró por ultra filtración (PM-10-Amicon, USA), se dializó y se determinó el contenido proteico ${ }^{13}$, usando albúmina bovina como standard interno.

Test de ELISA (EIE): Se realizó una prueba cuantitativo en fase sólida ${ }^{3}$, empleando antígeno TES en concentración de $0.1625 \mathrm{ug} / \mathrm{ml}$, inmovilizado sobre placas Maxisorp (NUNC Inc.USA) y suero anti IgG humana conjugado con peroxidasa de rábano picante (Sigma Inc.-USA) diluído 1:10.000. La reacción se reveló con ortofenilendiamina al $0,060 \%$, todos los sueros fueron estudiados por duplicado y las densidades ópticas leídas a $450 \mathrm{~nm}$, considerándose positivos a todos los sueros con título de IgG igual o mayor a 1/ $80^{9,14}$. 
El método cumplió los siguientes parámetros de calidad: sensibilidad del 92,1\%, especificidad del $87,5 \%$.

Fraccionamiento de los antígenos TES: Los Ags fueron fraccionados por electroforesis en geles de poliacrilamida con dodecil sulfato de sodio (SDS-PAGE) a concentración única. Para ello se emplearon geles de 70 x $80 \times 0,25 \mathrm{~mm}$ compuestos por soluciones de poliacrilamida al $5 \%$ (gel concentrador) y al $12 \%$ (gel separador) que se prepararon mezclando volúmenes adecuados de buffer TRIS-HCl 62 mM-pH 6.8, buffer TRIS-HCl pH 8.8, glicerol, solución de SDS al $10 \%$, solución de acrilamida-bis-acrilamida al $30 \%$, persulfato de amonio al $10 \%$ y TEMED, empleándose una celda Mini-protean II Slab Cell (Bio-Rad Labs, USA).

La concentración proteica del antígeno TES fue de $6 \mathrm{ug} / \mathrm{ml} \mathrm{y}$ antes de someterlo a la electroforesis fue diluido 1:3 en una solución reductora compuesta por tampón TRIS-HCl-pH $6.8,2 \%$ de SDS, $2 \%$ de ditiotreitol 0,02 M, 10\% de glicerol y $0,04 \%$ de azul de bromofenol y calentado a $100^{\circ} \mathrm{C}$ durante 5 min.

El PM de las fracciones obtenidas se calculó mediante una curva de calibración construida a partir de los PM de los marcadores empleados: miosina-200 kDa, beta-galactosidasa-116.25 $\mathrm{kDa}$, fosforilasa b-97.4 kDa, seroalbúmina bovina$66.2 \mathrm{kDa}$, ovoalbúmina-45 kDa, anhidrasa carbónica-31 kDa, inhibidor de la tripsina de soja$21.5 \mathrm{kDa}$, lisozima-14.4 kDa y aprotinina- $6.5 \mathrm{kDa}$ (Bio-Rad Labs., USA).

El buffer de electroforesis fue TRIS-Glicina pH 8.3 (Tris 0.025M, Glicina 0.192M, SDS $0.1 \%$ ) y las condiciones de corrida 30 minutos a $50 \mathrm{~V}$, seguidos de 70 minutos a $150 \mathrm{~V}$.

Electro transferencia: Se empleó un equipo Trans Blot Cell (Bio-Rad Labs, USA) y un buffer de transferencia TRIS-Glicina-Metanol pH 9.2 (TRIS $48 \mathrm{mM}$, Glicina $39 \mathrm{mM}$, Metanol 0,0375 $\%)$. La transferencia se efectuó sobre membrana de nitrocelulosa (Sigma Corp.-USA), durante 75 minutos a 100V. Finalizada la transferencia, las membranas se conservaron en sobres cerrados de aluminio a $4^{\circ} \mathrm{C}$ hasta su empleo en la reacción de inmunoblotting.

Immunoblotting (IB): Las membranas de nitrocelulosa se fraccionaron en tiras de $3 \mathrm{~mm}$ de ancho y se bloquearon durante 2 horas en solución de TBS-Tween-20 al 0,2\%, con un 5\% de leche descremada para eliminar los sitios de unión inespecífica. Las muestras de suero se diluyeron 1:50 en solución de TBS-Tween-leche descremada al $1 \%$ y se incubaron con las tiras a temperatura ambiente durante $60 \mathrm{~min}$ con agitación rotatoria permanente. Luego de tres lavados con solución de TBS-Tween sin leche, las tiras se incubaron durante 30 minutos a temperatura ambiente con anticuerpo anti-IgG humana conjugado con peroxidasa (Sigma Corp.USA) diluido 1:1.000 en buffer TBS-Tween-leche al $1 \%$, con agitación permanente en rotador. Los lavados se hicieron nuevamente con solución de TBS-Tween sin leche y finalmente con TBS. La reacción se reveló con diaminobencidina-Cloruro de níquel activado con $\mathrm{H}_{2} \mathrm{O}_{2}$ (Sigma Corp., USA).Se tomó como criterio de positividad la presencia de bandas de 24 a $35 \mathrm{kD}^{6}$.

\section{RESULTADOS}

Sobre la base de los títulos obtenidos en el test de ELISA, los sueros se clasificaron en Positivos de alto título (igual o mayor a 1/640), positivos de bajo título (entre $1 / 80$ y $1 / 320$ ) y en Negativos $(<$ de 1/80).

Las muestras con serología positiva y los controles positivos mostraron en el WB un patrón de bandas en el que se podían identificar claramente seis componentes con PMs de 67.6 $\mathrm{kDa}, 55.6 \mathrm{kDa}, 43.9 \mathrm{kDa}, 32.4 \mathrm{kDa}, 26.6 \mathrm{kDa} \mathrm{y}$ $23.4 \mathrm{kDa}$. (Figura 1). Los sueros de control negativo de área endémica y no endémica no mostraron bandas.

El análisis de la correlación entre el test de EIE y el IB demostró que el 100\% de las muestras positivas con altos títulos de IgG presentaba un Inmunoblotting positivo, mientras que en las muestras con títulos bajos y en las negativas se observaron algunas discrepancias (Tabla 1).

Del total de las 180 muestras estudiadas, en 172 se obtuvieron resultados coincidentes por ambos métodos (correlación del 95,6\%), 6

Tabla 1. Correlación entre los métodos de ELISA y Western Blot

\begin{tabular}{lcrcr}
\hline Test & \multicolumn{2}{c}{ ELISA (+) } & ELISA (-) & Total \\
& $\begin{array}{c}\text { Títulos } \\
\text { altos }\end{array}$ & $\begin{array}{c}\text { Títulos } \\
\text { bajos }\end{array}$ & & \\
\hline WB (+) & 86 & 34 & 6 & 126 \\
WB (-) & 0 & 2 & 52 & 54 \\
Total & 86 & 36 & 58 & 180 \\
\hline
\end{tabular}




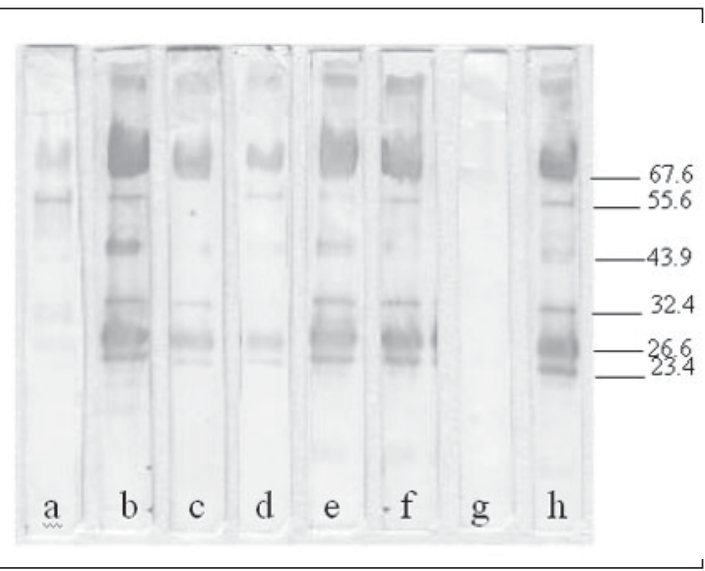

Figura 1. Immuno Blotting con antígeno E/S de Toxocara canis. (a-f: muestras; g: control negativo; h: control positivo).

muestras negativas por EIE resultaron positivas por WB $(3,3 \%)$ y dos muestras positivas con títulos bajos por EIE fueron negativas por WB $(1,1 \%)$.

\section{DISCUSIÓN}

En los casos de larva migrans visceral el diagnóstico definitivo sólo puede ser alcanzado con el hallazgo de las larvas migrantes en el examen histopatológico de muestras de diferentes órganos, como ser hígado, pulmón o cerebro ${ }^{2}$, mientras que en los casos de afectación ocular la larva móvil puede llegar a ser observada en forma directa bajo la retina ${ }^{15}$. Sin embargo, cualquiera de estas situaciones es de difícil abordaje y de resultados inseguros. Frente a estas limitaciones y a la inexistencia de una prueba de referencia internacional, se ha recomendado el empleo del Western blot, que es tan sensible como el test de ELISA pero de mayor especificidad, particularmente cuando se observa la presencia de anticuerpos dirigidos contra las fracciones mas livianas de 25 a $40 \mathrm{kDa}^{6}$.

El antígeno TES muestra un extenso patrón de bandas que van desde los 20 a los $400 \mathrm{kDa}^{4}$. Para resolver este espectro tan amplio algunos autores han recurrido al empleo de geles de poliacrilamida con gradientes de concentración, que permiten separar mezclas polipeptídicas complejas ${ }^{7}$. Como la finalidad del presente trabajo era simplificar el método de inmunoblotting con condiciones operativas más sencillas, se decidió trabajar con geles de concentración única pero eligiendo una que pudiera resolver eficientemente las bandas correspondientes a los polipéptidos de bajo peso molecular y evitar así la reacción cruzada con otros ascáridos ${ }^{7,16}$.

Con las condiciones aplicadas hemos encontrado un patrón característico donde se identifican seis componentes reconocidos por anticuerpos IgG, cinco de los cuales correlacionan de modo casi perfecto con las glicoproteínas TES caracterizadas por previamente y designadas como TES-26, TES-32, TES-45, TES-55, y TES$70^{4,5}$. Según lo referido por estos autores, en los casos seropositivos se detectan siete bandas clasificadas en dos grupos: uno correspondiente a las bandas de bajo peso molecular (28-30 y 45 $\mathrm{kDa}$ ) y otro correspondiente a las de alto peso (132-147 y $200 \mathrm{kDa}$, habiéndose señalado que estas últimas serían las responsables de la reactividad cruzada, mientras que las primeras serían las específicas del género Toxocara ${ }^{2}$. Los anticuerpos que se pueden demostrar con las condiciones técnicas descriptas en este trabajo corresponden exactamente a las livianas.

El número de bandas que se pueden reconocer mediante el immunoblotting así como sus PMs varían de una publicación a otra, lo que se puede atribuir a las condiciones de trabajo, al marcador de peso usado y a otros factores inherentes al ensayo. En este sentido, se pueden citar los resultados que identificaron cinco componentes principales, uno mayor a $205 \mathrm{kDa}$ y otros de 205 , $116-97,55-50$ y $35-29 \mathrm{kDa}^{7}$, y los ya referidos ${ }^{6}$.

Hemos observado un buen grado de especificidad con el patrón de bandas descrito en este trabajo, ya que ninguno de los sueros de control negativo de área endémica de toxocarosis mostraron reacción positiva con alguna de las bandas antigénicas identificadas. Por otro lado, en los casos positivos la intensidad de las bandas se correlacionó claramente con el título de anticuerpos obtenido en el ensayo de ELISA cuantitativo; a mayor título serológico, mayor intensidad de las bandas.

El hallazgo de dos sueros ELISA positivos con bajo título y WB negativo es comprensible tratándose de muestras procedentes de una población de área subtropical en la que las parasitosis son prevalentes. Contrariamente, las 6 muestras ELISA negativas que mostraron bandas en el WB podrían tratarse de casos con una concentración de anticuerpos baja, por debajo del valor de cutt-off aceptado. 
La correlación hallada entre ambos métodos es coincidente con las informadas por otros autores $^{6,16}$, por lo cual se concluye que el ensayo de inmunoblotting acá descrito constituiría un método adecuado para el diagnóstico de toxocariasis, particularmente útil en los casos de áreas endémicas en los que el test de ELISA resulte negativo o positivo con títulos bajos, y en presencia de signos y/o síntomas de la infección.

\section{RESUMEN}

El diagnóstico de toxocariosis se basa en la demostración de anticuerpos mediante enzimoinmunoensayos, aunque en poblaciones de área tropicales suelen ocurrir reacciones cruzadas con otros ascáridos. Por ello algunos autores han propuesto el Western Blot como test confirmatorio. El objetivo de este trabajo fue desarrollar un método de immunoblotting con condiciones técnicas sencillas y comparar su comportamiento con la reacción de enzimoinmunoensayo. Se estudiaron 180 muestras de suero de adultos y niños con signo-sintomatología compatible con toxocariosis. Se efectuó test de ELISA con Antígenos TES, seleccionándose 120 sueros positivos y 60 negativos, los que fueron analizados nuevamente por immunobloting y se compararon los resultados de ambos métodos. Las muestras y controles positivos mostraron en el WB un patrón de seis bandas con PMs de 67,6 kDa, 55,6 $\mathrm{kDa}, 43,9 \mathrm{kDa}, 32,4 \mathrm{kDa}, 26,6 \mathrm{kDa}$ y 23,4 kDa. Los sueros de control negativo de área endémica y no endémica de toxocarosis no mostraron banda alguna. De 180 muestras estudiadas, en 172 se obtuvieron resultados coincidentes por ambos métodos $(95,6 \%), 6$ muestras negativas por ELISA resultaron positivas por Western Blot $(3,3 \%)$ y dos muestras positivas por ELISA fueron negativas por Western Blot $(1,1 \%)$. El ensayo de immunoblotting acá descrito constituiría un método adecuado para el diagnóstico de toxocariosis en áreas subtropicales, particularmente útil en los casos en los que el test de ELISA resulte negativo o positivo con títulos bajos y en presencia de signos y/o síntomas de la infección.

\section{REFERENCIAS}

1.- MINVIELLE M C, NIEDFELD G, CIARMELA M L, BASUALDO J A. Toxocariosis causada por Toxocara canis: aspectos clinicoepidemiológicos. Enferm Infecc Microbiol Clin 1999; 17: 300-6.

2.- MAGNAVAL J F, GLICKMAN L T, et al. Highlights of human toxocariasis. The Korean J Parasitol 2001; 39: 1-11.

3.- SAVIGNY D H, VOLER A, WOODRUFF A N. Toxocariasis: serological diagnosis by Enzyme Immunoassay. J Clin Pathol 1979; 32: 284-8.

4.- MAIZELS R, DE SAVIGNY D, OGILVIE B. Characterization of surface and excretory-secretory antigens of Toxocara canis infective larvae. Parasite Immunol 1984; 6: 23-37.

5.- MAIZELS R M, TETTEH KK, LOUKAS A. Toxocara canis: genes expressed by the arrested infective larval stage of a parasitic nematode. Int J Parasitol 2000; 30: 495-508.

6.- MAGNAVAL J, FABRE R, MAURIERES P, et al. Application of the western blotting procedure for the immunodiagnosis of human toxocariosis. Parasitol Res 1991; 77: 697-702.

7.- NUNES C M, TUNDISI R N, GARCÍA J F, et al. Crossreactions between Toxocara canis and Ascaris suum in the diagnosis of visceral larva migrans by western blotting technique. Rev Inst Med trop S. Paulo 1997; 39: 253-6.

8.- ALONSO J M, BOJANICH M V, CHAMORRO M, GORODNER J O. Toxocara seroprevalence in children from a subtropical city in Argentina. Rev Inst Med trop S. Paulo 2000; 42: 235-7.

9.- ALONSO J M, LÓPEZ M A, BOJANICH M V, MARULL J. Infección por Toxocara canis en población adulta sana de un área subtropical de Argentina. Parasitol Latinoam 2004; 59: 61-4.

10.- GUILLERÓN D C, ALONSO J M, PICÓN D. Estudio coproparasitológico en escolares de la ciudad de Resistencia. Arch Arg Pediatría 1984; 82: 224-6.

11.- GILLESPIE S H. Migration worms. Medical Parasitology. A Practical Approach. Oxford University Press. 1995

12.- GUPTA A K. A simple method of artificial hatching of Toxocara canis in vitro and preparation of excretory/secretory antigen. Currents Science 1984; 53: 529-30.

13.- BRADFORD M M. A rapid and sensitive method for cuantitation of microgram quantities of protein utilizing of protein dye binding. Anal Biochem 1976; 72: 248-54

14.- BOJANICH M V, ALONSO J M, CHAMORRO M. Enzimoinmunoensayo para el diagnóstico de toxocariosis. Comunicaciones Científicas y Tecnológicas $\mathrm{N}^{\circ}$ 14, UNNE, 2000, Disponible en: // www.unne.edu.ar/Web/cyt/cyt/2000/cyt.htm; consultado 12-5-2005.

15.- DE SOUZA E C, NAKASHIMA Y. Diffuse unilateral sub acute neuroretinitis. Report of transvitreal surgical removal of a sub retinal nematode. Ophthalmology 1995; 102: 1183-6.

16.- MORALES O, LÓPEZ M, NICHOLLS R. Identification of Toxocara canis antigens by western blot in experimentally infected rabbits. Rev Inst Med Trop S Paulo 2002; 44: 213-6.

Agradecimientos: Este trabajo fue parcialmente financiado con el Subsidio PI-254 de la Secretaría General de Ciencia y Técnica de la Universidad Nacional del Nordeste (Argentina). 